\title{
The risk for delayed development in low birth weight, appropriate for gestational age preterm infants
}

\author{
Stanza Uga Peryoga, MD; Abdurachman Sukadi, MD; Sambas Wiradisuria, MD
}

\begin{abstract}
Background Preterm infants, particularly those who have had severe asphyxia, hyperbilirubinemia, and sepsis, tend to be at risk for neurodevelopmental impairment.

Objective The purpose of this study was to assess the risk for delayed development in low birth weight (LBW), appropriate for gestational age (AGA) preterm infants compared to that in term, non-LBW infants, and to investigate the roles of severe asphyxia, sepsis, and hyperbilirubinemia as potential risk factors for delayed development. Methods This was a hospital-based retrospective cohort study involving preterm, LBW and term, non-LBW infants conducted in Hasan Sadikin Hospital, Bandung. The Bayley Infant Neurodevelopmental Screener (BINS) test was performed to assess the risk of delayed development at 3 months of corrected age for the preterm infants and at 3 months of chronological age for the term infants. Bivariate analysis using the chi-square test and multivariate analysis using logistic regression were performed.

Results One hundred and twelve infants fulfilled eligibility criteria, consisting of 52 preterm, LBW and 60 term, non-LBW infants. Based on the BINS test, of the preterm, LBW infants, $32(61 \%)$ were at low risk, $11(21 \%)$ at moderate risk, and $9(17 \%)$ at high risk for delayed development. Of the control infants, $49(82 \%)$ were at low risk, $10(17 \%)$ at moderate risk, and $1(1.7 \%)$ at high risk for delayed development. Logistic regression analysis showed significant association between accompanying diseases such as sepsis $(\mathrm{OR}=25.60 ; \mathrm{P}=0.001)$ and hyperbilirubinemia $(\mathrm{OR}=16.07 ; \mathrm{P}=0.001)$ with delayed development. Despite more than twofold odds for delayed development in infants with severe asphyxia $(\mathrm{OR}=2.51)$ and LBW-prematurity $(\mathrm{OR}=2.47)$, the association was statistically insignificant ( $P=0.20$ and $P=0.15$, respectively).

Conclusions In preterm infants appropriate for gestational age, prematurity and low birth weight alone may or may not predispose to delayed development at 3 months of age. However, the risk for delayed development in such infants is increased when sepsis or hyperbilirubinemia is present [Paediatr Indones 2005;45:154159].
\end{abstract}

Keywords: preterm, low birth weight, developmental delay, Bayley Infant Neurodevelopmental Screener

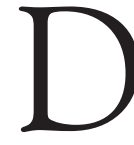
elayed development in high-risk infants is caused either by existing biological, psychosocial environment, or social economic risk factors. ${ }^{1}$ Preterm infants are at risk for delayed development due to the immaturity of their organs. ${ }^{2}$ The occurrence of delayed development may also be a consequence of accompanying diseases such as asphyxia, hyperbilirubinemia, sepsis, periventricular hemorrhage, and chronic lung disease. ${ }^{3,4}$

Aside from infectious diseases and malnutrition, low birth weight (LBW) is a significant cause of child morbidity and mortality, as well as a risk factor for delayed development in later life. ${ }^{5}$ In Indonesia, the incidence of LBW is still high, both in rural $(10 \%)$ or urban (20\%) areas. ${ }^{6}$ However, the outcome of infants with birth weight of 1500-2499 $\mathrm{g}$ is less frequently reported than that of those weighing less than $1500 \mathrm{~g}$ at birth. In Indonesia, the risk for delayed development is predicted to be different from that in developed countries, considering the abundance of biological and environmental risk factors. The incidence, mortality, and morbidity of LBW infants in Indonesia

From the Department of Child Health, Medical School, Padjadjaran University, Hasan Sadikin Hospital, Bandung, Indonesia.

Reprint requests to: Stanza Uga Peryoga, MD, Department of Child Health, Medical School, Padjadjaran University, Hasan Sadikin Hospital, Jl. Pasteur No. 38, Bandung 40161, Indonesia. Tel. 62-22-2034426; Email: bikaup@bdg.centrin.net.id, office@pediatry.fk.unpad.ac.id. 
are still high. ${ }^{6,7}$ To assess an infant's developmental status, an early developmental screening test needs to be done periodically. ${ }^{8}$ To date, no study has been reported on the risk for delayed development at an early age (3 months) in LBW, appropriate for gestational age (AGA) infants using the Bayley Infant Neurodevelopmental Screener (BINS) as screening instrument. The purpose of this study was to assess the risk for delayed development in LBW (1500-2499 g), AGA preterm infants compared to that in term, non-LBW infants. The roles of accompanying conditions, such as severe asphyxia, sepsis, and hyperbilirubinemia as potential risk factors for delayed development were also investigated.

\section{Methods}

This was an observational study with a retrospective cohort design involving LBW, AGA preterm infants born in March-August 2003 and term, non-LBW infants born in June-July 2003 at Hasan Sadikin Hospital, Bandung. The subjects were recruited at birth by consecutive sampling. Subjects included in the LBW, preterm group were singleton, appropriate for gestational age preterm infants with birth weight of 1500-2499 g at 3 months of corrected age. The control group consisted of term infants appropriate for gestational age with birth weight of $\geq 2,500 \mathrm{~g}$ at 3 months of age, who had no history of illness since birth. All infants had to be in good health. We obtained parental written informed consent from all subjects. Exclusion criteria were major congenital anomaly (e.g., Down syndrome, meningocele), congenital infection (TORCH), hyaline membrane disease, and history of exchange transfusion, prior hospital admission, seizures, and head trauma. To assess the risks for delayed development, the Bayley Infant Neurodevelopmental Screener (BINS) test was performed. The BINS test was administered during home visits or at the outpatient Growth and Development Clinic of Hasan Sadikin Hospital.

All data were recorded, tabulated, and analyzed using SPSS version 10.0 for Windows. To determine the association between prematurity, low birth weight, and its accompanying diseases with the risk for delayed development, we performed bivariate analysis using the chi-square test. To determine the influence of other independent variables such as severe asphyxia, sepsis, and hyperbilirubinemia, we performed multivariate analysis using logistic regression. In bivariate and multivariate analysis, the risk for delayed development was divided into low, moderate, and high risk. A P value of $<0.05$ was considered statistically significant. Odds ratio (OR) with 95\% confidence intervals $95 \%$ were calculated. Probabilities of risk for delayed development from various risk factors were estimated using the logistic regression model.

Ethical approval for this study was obtained from the Research Ethics Committee of the Medical School, Padjadjaran University.

\section{Results}

According to the perinatology medical records in March-August 2003, 85 infants fulfilled the inclusion criteria for the LBW, preterm group. We were unable to locate the homes of 33 of these infants. At the end of the study, there were 52 infants in the preterm, LBW group, of which 38 were examined in the clinic and 14 were home visited. Developmental examination in this group was conducted in July 2003 to January 2004. In the control group there were 60 infants. Examination in this group was performed at the clinic in September-November 2003.

Table 1 shows the characteristics of subjects in both groups, which appear to be similar. The risks for delayed development in both groups are shown in Table 2. In bivariate analysis, significant difference was found between both groups in the proportions of infants with low risk $(\mathrm{P}=0.02)$ and high risk $(\mathrm{P}=0.001)$ for delayed development. However, such a difference was not found for moderate risk $(\mathrm{P}=0.54)$.

Table 3 depicts the performance of infants in each group on each item of the BINS examination. Using chi square test, significant differences between both groups were found in the ability to hold the head erect and steady for 15 seconds $(\mathrm{P}=0.001)$, to adjust the head to ventral suspension $(\mathrm{P}=0.04)$, and to sit with slight support for 10 seconds $(P=0.001)$. Significantly less infants in the preterm, LBW group than in the control group were able to perform these items.

The proportions of infants with accompanying morbidities at birth, such as asphyxia, hyperbilirubinemia, and sepsis can be seen in Table 4. Severe asphyxia 
Table 1. Subject characteristics

\begin{tabular}{|c|c|c|}
\hline \multirow[t]{2}{*}{ Characteristic } & \multicolumn{2}{|l|}{ Group } \\
\hline & $\begin{array}{l}\text { Preterm, LBW } \\
(n=52)\end{array}$ & $\begin{array}{l}\text { Term, Non-LBW } \\
(n=60)\end{array}$ \\
\hline \multicolumn{3}{|l|}{ Sex } \\
\hline Male & $26(50 \%)$ & 24 (40\%) \\
\hline Female & $26(50 \%)$ & $36(60 \%)$ \\
\hline \multicolumn{3}{|c|}{ Gestational age (weeks) } \\
\hline Mean (SD) & $34.8(1.4)$ & $38.8(1.0)$ \\
\hline Range & $32-36$ & $37-41$ \\
\hline \multicolumn{3}{|l|}{ Birth weight (g) } \\
\hline Mean (SD) & $2038.6(246.1)$ & $3178.9(324.1)$ \\
\hline Range & $1500-2450$ & $2500-4000$ \\
\hline \multicolumn{3}{|c|}{ Birth length (cm) } \\
\hline Mean (SD) & $43.5(3.4)$ & $49.2(2.2)$ \\
\hline Range & $30-52$ & $43-53$ \\
\hline
\end{tabular}

TABle 2. The RISK FOR DELAYED DEVELOPMENT IN BOtH GROUPS

\begin{tabular}{llllll}
\hline Risk for delayed & \multicolumn{5}{c}{ Group } \\
\cline { 2 - 6 } development & \multicolumn{1}{l}{ Preterm, LBW } & \multicolumn{2}{l}{ Term, Non-LBW } & P \\
\cline { 2 - 6 } & $\mathbf{N}$ & $\%$ & $\mathbf{N}$ & $\%$ & \\
\hline Low & 32 & 61.5 & 49 & 81.7 & $0.02^{*}$ \\
Moderate & 11 & 21.2 & 10 & 16.7 & 0.54 \\
High & 9 & 17.3 & 1 & 1.7 & $0.001^{*}$ \\
\hline
\end{tabular}

Table 3. Results of Bins examination

\begin{tabular}{|c|c|c|c|c|c|}
\hline \multirow[t]{3}{*}{ Item on BINS } & \multicolumn{4}{|c|}{$(\%)$} & \multirow[t]{3}{*}{$\mathbf{P}$} \\
\hline & \multicolumn{2}{|c|}{ Preterm, LBW } & \multicolumn{2}{|c|}{ Term, Non-LBW } & \\
\hline & Non- optimal & Optimal & Non- optimal & Optimal & \\
\hline 1. Eyes follow ring & 1.9 & 98.1 & 1.7 & 98.3 & 0.72 \\
\hline 2. Reaches for suspended ring & 75 & 25 & 58.3 & 41.7 & 0.06 \\
\hline 3. Holds head erect and steady for 15 seconds & 25 & 75 & 3.3 & 96.7 & $0.001^{*}$ \\
\hline 4. Adjusts head to ventral suspension & 7.7 & 92.3 & - & 100 & $0.04^{*}$ \\
\hline $\begin{array}{l}\text { 5. Demonstrates optimal muscle tone in upper } \\
\text { extremities }\end{array}$ & - & 100 & - & 100 & - \\
\hline $\begin{array}{l}\text { 6. Demonstrates optimal muscle tone in lower } \\
\text { extremities }\end{array}$ & 1.9 & 98.1 & - & 100 & 0.46 \\
\hline 7. Sits with slight support for 10 seconds & 57.7 & 42.3 & 28.3 & 71.7 & $0.001^{*}$ \\
\hline 8. Regards pellet-conjugate gaze & 5.8 & 94.2 & 6.7 & 93.3 & 0.58 \\
\hline 9. Vocalizes two different sounds & 15.4 & 84.6 & 5.0 & 95.0 & 0.07 \\
\hline 10. Fingers hands in play & 36.5 & 63.5 & 36.7 & 63.3 & 0.99 \\
\hline $\begin{array}{l}\text { 11. Demonstrates coordinated movement of } \\
\text { extremities }\end{array}$ & 1.9 & 98.1 & - & 100 & 0.46 \\
\hline
\end{tabular}

TABle 4. AcCOMPANYING MORBIDITY

\begin{tabular}{llllll}
\hline Morbidity & LBW & \multicolumn{3}{l}{ Non-LBW } & P \\
\cline { 2 - 6 } & $\mathbf{N}$ & $\%$ & $\mathbf{N}$ & $\%$ & \\
\hline Without asphyxia & 21 & 40.4 & 39 & 65.0 & 0.01 \\
Mild to moderate asphyxia & 18 & 34.6 & 17 & 28.3 & 0.47 \\
Severe asphyxia & 13 & 25.0 & 4 & 6.7 & 0.01 \\
Hyperbilirubinemia & 9 & 17.3 & 11 & 18.3 & 0.89 \\
Sepsis & 11 & 21.2 & 2 & 3.3 & 0.001 \\
\hline
\end{tabular}


Stanza Uga Peryoga et al: The risk for delayed development in preterm infants

TABle 5. Logistic REgRession anAlysis on the ASSOCIATION BETWEen POTENTIAL RISK FACTORS AND THE RISK OF DELAYED DEVELOPMENT

\begin{tabular}{llllll}
\hline Risk factor & $\boldsymbol{\beta}$ & SE & $\mathbf{P}$ & OR & Cl 95\% \\
\hline LBW-prematurity & 0.90 & 0.63 & 0.15 & 2.47 & $0.72 ; 8.42$ \\
Severe asphyxia & 0.92 & 0.72 & 0.20 & 2.51 & $0.62 ; 10.22$ \\
Sepsis & 3.24 & 1.17 & $0.001^{*}$ & 25.60 & $2.61 ; 251.22$ \\
Hyperbilirubinemia & 2.78 & 0.74 & $0.001^{*}$ & 16.07 & $3.80 ; 67.98$ \\
\hline
\end{tabular}

$\beta$ : regression coefficient; constant: -2.545 ; accuracy: $85.7 \%$

$(\mathrm{P}=0.01)$ and sepsis $(\mathrm{P}=0.001)$ was significantly more prevalent in the preterm, LBW group than in the control group. Such a difference was not found for mild to moderate asphyxia and hyperbilirubinemia.

From bivariate analysis, we obtained a statistically significant association between sepsis and hyperbilirubinemia with the risk for delayed development $(\mathrm{P}=0.001)$. However, there was no significant association between severe asphyxia and the risk for delayed development $(\mathrm{P}=0.15)$.

On logistic regression analysis, it was shown that sepsis $(O R=25.60,95 \% C I$ 2.61; 251.22) and hyperbilirubinemia $(\mathrm{OR}=16.07,95 \% \mathrm{CI} 3.80 ; 67.98)$ were significantly associated with the risk for delayed development. Low birth weight-prematurity $(\mathrm{OR}=2.47)$ and severe asphyxia $(\mathrm{OR}=2.51)$ potentially increased the odds for delayed development by more than twofold, but in the population the effects of these two factors may vary $(95 \%$ CI $0.72 ; 8.42$ and $0.62 ; 10.22$, respectively) (Table 5).

\section{Discussion}

In this study, the number of participants examined in the preterm, LBW group were less than initially planned because we could not find the residences of some patients. There were no participants with very low birth weight $(<1500 \mathrm{~g})$, despite our knowledge that approximately $50 \%$ of these infants are at risk for delayed development. ${ }^{9}$ From medical records, we found that most of these very low birth weight (VLBW) infants died during hospitalization; those who survived died after they had been discharged.

The Bayley Infant Neurodevelopmental Screener (BINS) is designed to identify infants between the ages of 3 to 24 months who are developmentally delayed of have neurological impairments.
It is not an abbreviated form of the Bayley Scales of Infant Development-Second Edition (BSID-II), but rather a tool for screening infants to identify them for further diagnostic testing. ${ }^{10}$ The results of developmental screening test using BINS showed differences in the degree of risk for delayed development between both groups. A larger proportion of LBW, preterm infants were at high risk $(17 \%)$ compared to non-LBW, term infants (2\%). We found that the proportion of LBW, preterms at high risk for delayed development was higher than that in the United States $(8 \%, 95 \%$ CI 5;20\%). In the United States it was also found that LBW, preterm infants had 2-5 times higher risk for delayed development than nonLBW, term infants. ${ }^{11}$

Premature and low birth weight infants tend to have higher risk for neurological disorder and delayed development. ${ }^{12}$ Moreover, they often have subnormal growth and inferior health conditions. ${ }^{13}$ Dunn et al revealed that motor disorders often correlate with prematurity. ${ }^{14}$ From Table 3, we see that delayed development in motor-neurologic aspects (holding head erect and steady for 15 seconds, adjusting head to ventral suspension) and expressive aspects (sitting with slight support, vocalizes sound) were profound in the LBW, preterm group.

Lenke ${ }^{15}$ found that the prevalence of motor disorders was 35\% in LBW infants (1501-2000 g) and 60$70 \%$ in VLBW infants $(<1500 \mathrm{~g})$. The types of motor disorders were increased or decreased muscle tone, impaired automatic reaction, persistent primitive reflex, and asymmetric neuromotor development. All these conditions gradually improved and became normal at 8-10 months' corrective age. Transient dystonia, a transient motor disorder resolved in the first year of life. ${ }^{15}$

Premature infants often experience other conditions such as sepsis, severe asphyxia, hyperbilirubinemia, intraventricular hemorrhage (IVH), and cerebral infarc- 
tion. All these conditions can aggravate neurological impairments. In our study we did not have any data on IVH or infarct due to lack of supporting devices (USG).

Fifteen percent of term infants who experience hypoxic ischaemic encephalopathy (HIE) due to severe asphyxia will have persisting brain function impairment and develop cerebral palsy or mental retardation. ${ }^{13}$ In this study, severe asphyxia had no significant correlation with delayed development. Similarly, Gottoff ${ }^{16}$ wrote that only 10\% infants with cerebral palsy had experienced severe asphyxia. This might be because most infants with severe asphyxia had died before the study. It is still being debated whether it is justified to use the Apgar score as a sole determinant for severe asphyxia, and then associate it with the risk for delayed development.

In this study, prematurity alone was not a risk factor for delayed development. However, if this condition is accompanied with sepsis and/or hyperbilirubinemia $(>15 \mathrm{mg} / \mathrm{dl})$, the risk became profound. Sepsis had the strongest correlation with delayed development, whereas hyperbilirubinemia had significant correlation in multivariate analysis.

To detect the possibility of delayed development at later age, we recommend all subjects who had high risk for delayed development to have a repeat developmental assessment 2 weeks after the first assessment. We also referred them for neuropediatric, ENT, and eye examinations, as well as rehabilitation if needed. ${ }^{5}$ Subjects who had moderate risk were recommended to undergo developmental examination every 3 months. The subjects should be followed until the age 18-24 months to diagnose delay and enable prompt intervention. Assessment before school entry is needed to evaluate minor disorders, particularly in fine motor ability, visuomotor aspect, and learning behavior.

We conclude that preterm, AGA, LBW infants are not necessarily at risk for delayed development at 3 months' corrected age. Conditions which increase the risk for delayed development were sepsis and hyperbilirubinemia. Our findings underline the importance of providing best perinatal care to prevent postnatal complications that may lead to delayed development.

\section{Acknowledgments}

We are indebted to the subjects and their parents who provided all the information for this study. We thank Prof. Herry Garna, MD, $\mathrm{PhD}$; Prof. Dedi Subardja, MD, PhD; and Prof. Abdurachman
Sukadi, $\mathrm{MD}, \mathrm{PhD}$ for providing valuable advice, correcting the manuscript, and giving the support which made this study possible.

\section{References}

1. Bennett FC. Developmental outcome. In: Avery GB, Fletcher M, MacDonald MG, editors. Neonatology: Pathophysiology and management of the newborn. $5^{\text {th }}$ edition. Philadelphia: JB Lippincott; 1999. p. 1479-97.

2. Allen MC. Outcome and follow-up high-risk infants. In: Taeusch HW, Ballard RA, editors. Avery's diseases of the newborn. $7^{\text {th }}$ edition. Philadelphia: WB Saunders; 1998. p. 413-28.

3. Allen MC. The high-risk infant. Pediatr Clin North Am 1993;40:479-90.

4. Stoll BJ, Kliegman RM. The high-risk infant. In: Behrman RE, Kliegman RM, Jenson HB, editors. Nelson textbook of pediatrics. $16^{\text {th }}$ edition. Philadelphia: WB Saunders; 2000. p. 474-85.

5. Adhikari M. Problems of the preterm infant. In: Bassin J, Ginsberg ND, editors. Topics in pediatrics. Johannesburg: Julmar Communications; 1996. p. 19-27.

6. Usman A, Alisjahbana A. Preliminary report on perinatal mortality and low birth weight infant in Tanjungsari [unpublished data]. Bandung; 1988.

7. Departemen Kesehatan Republik Indonesia. Profil Kesehatan Indonesia. Jakarta: Pusat Data Kesehatan; 1998.

8. Aylward GP, Pfeiffer SI, Wright A, Verhulst J. Outcome studies of low birth weight infants published in the last decade: a meta-analysis. J Pediatr 1989;115:515-20.

9. Hack M, Klein NK, Taylor HG. Long term developmental outcomes of low birth weight infants. The Future of Children 1995;5:176-96.

10. Escobar GJ, Littettnberg B, Petitti DB. Outcome among surviving very low birth weight infants: A meta analysis. Arch Dis Child 1991;66:204-11.

11. Aylward GP. Bayley infant neurodevelopmental screener. $2^{\text {nd }}$ edition. San Antonio: The Psychological Corporation; 1995.

12. Soetjiningsih. Tumbuh kembang anak. In: Ranuh IGN, editor. Tumbuh kembang anak. Jakarta: EGC; 1995. p. 1-32.

13. Aylward GP. The relationship between environmental risk and development outcome. J Dev Behav Pediatr 1992;13:3-20.

14. Dunn HG, Robertson AM, Crichton JU. Clinical outcome: Neurological sequelae and their evolution. $1^{\text {st }}$ 
edition. London: Mac Keith Press; 1986. p. 68-96.

15. Lenke MC. Motor outcome in premature infants. Cited_2003 October 1. Available from: URL: http:// www.medscape.com/viewarticle/461577.

16. Gottoff SP. Infections of the neonatal infant. In: Behrman RE, Kliegman RM, Jenson HB, editors.
Nelson textbook of pediatrics. $16^{\text {th }}$ ed. Philadelphia: WB Saunders Co; 2000. p. 538-51.

17. Narendra M. Penilaian pertumbuhan dan perkembangan anak. In: Narendra M, Sularyo S, Soetjiningsih, editors. Tumbuh kembang anak dan remaja. Jakarta: Sagung Seto; 2002. p. 95-111. 